\title{
Single origin of right and left pulmonary arteries from ascending aorta, with main pulmonary artery from right ventricle
}

\author{
ALBRECHT BEITZKE AND ELLIOT A SHINEBOURNE \\ From the Departments of Paediatric Cardiology, The Children's Hospital, University of Graz, \\ Austria, and the Brompton Hospital, London
}

SUMMARY A previously undescribed anomaly is presented in which right and left pulmonary arteries arise via a single vessel from the ascending aorta while the main pulmonary artery arises normally from the right ventricle. This main pulmonary artery has no branches supplying the lungs and connects via a ductus arteriosus to the descending aorta. Additional anomalies were an atrial septal defect and tubular hypoplasia of the aortic isthmus.

This baby boy was the first child of a 28 -year-old healthy woman. The pregnancy was uneventful; caesarean section was performed because of small pelvis and postmaturity. The baby required resuscitation after birth. Arterial blood gases from an umbilical arterial catheter one hour after birth showed normal $p \mathrm{H}$ and $\mathrm{PCO}_{2}$ but a $\mathrm{Po}_{2}$ of $36 \mathrm{mmHg}$. At 13 hours the baby was referred to the Children's University Hospital, Graz, because of persistent cyanosis, hepatomegaly, and tachypnoea. On admission there was central cyanosis, tachypnoea up to $80 /$ minute, and $2 \mathrm{~cm}$ hepatomegaly. The heart rate was 180 /minute, there was a loud pulmonary component to the second sound, and a grade $3 / 6$ ejection systolic murmur maximal at the second left intercostal space. All pulses were easily palpable and equal with a systolic pressure of $60 \mathrm{mmHg}$. $p \mathrm{H}$ was $7 \cdot 4, \mathrm{PCO}_{2} 40 \mathrm{mmHg}, \mathrm{Po}_{2}$ breathing 100 per cent $\mathrm{O}_{2}$ $60 \mathrm{mmHg}, \mathrm{Hb} 16.3 \mathrm{~g} / \mathrm{dl}$, haematocrit 60 per cent.

The chest $x$-ray film showed cardiac enlargement with increased pulmonary vascular markings. Electrocardiogram showed sinus rhythm, mean frontal $Q R S$ axis $+150^{\circ}$, and right ventricular hypertrophy. At cardiac catheterisation there were equal atrial pressures. Right ventricular and pulmonary arterial systolic pressures were $105 \mathrm{mmHg}$ compared with $75 \mathrm{mmHg}$ in the left ventricle and aorta. The catheter passed from the right ventricle to the pulmonary trunk and to the descending aorta via a ductus arteriosus. It was not possible to enter branches of the main pulmonary artery. A Swan Gan= catheter was manipulated from the left ventricle into the ascending aorta and into a large vessel originating from its posterior aspect. A left ventriculogram (Fig. 1a and b) showed a normal left ventricle from which arose the aorta. There was a left aortic arch. Arising from the posterior aspect of the ascending aorta was a short single vessel that divided into right and left pulmonary arteries. The right ventricular injection showed this chamber to be normal (Fig. 2a) while neither of the ventricular injections demonstrated a ventricular septal defect. An anterior main pulmonary artery arose anteriorly from the right ventricle but no right or left pulmonary arteries arose from it. The main pulmonary artery continued as a narrowed ductus arteriosus (Fig. $2 \mathrm{~b}$ and 3 ), both arterial valves were outlined, and moderate aortic isthmal narrowing was seen. The full diagnosis was situs solitus with atrioventricular and ventriculoarterial concordance, atrial septal defect, hypoplastic aortic isthmus, and abnormal origin of a vessel arising from the ascending aorta supplying right and left pulmonary arteries. The infant's condition deteriorated. Surgery was attempted on the 11th day of life. The vessel arising from the ascending aorta was dissected and connected with the solitary pulmonary trunk arising from the right ventricle. The ductus was ligated and divided. The infant did not come off bypass and died. Necropsy confirmed the angiographic diagnosis.

\section{Discussion}

In contrast to the aberrant origin of one pulmonary artery from the ascending aorta either as an isolated anomaly (Sanger et al., 1965; Winship et al., 1967; Kuypers et al., 1969; Keane et al., 1974) or in association with intracardiac defects (Flege et al., 1970; Kuers and McGoon, 1973; Keane et al., 
(a)

(b)
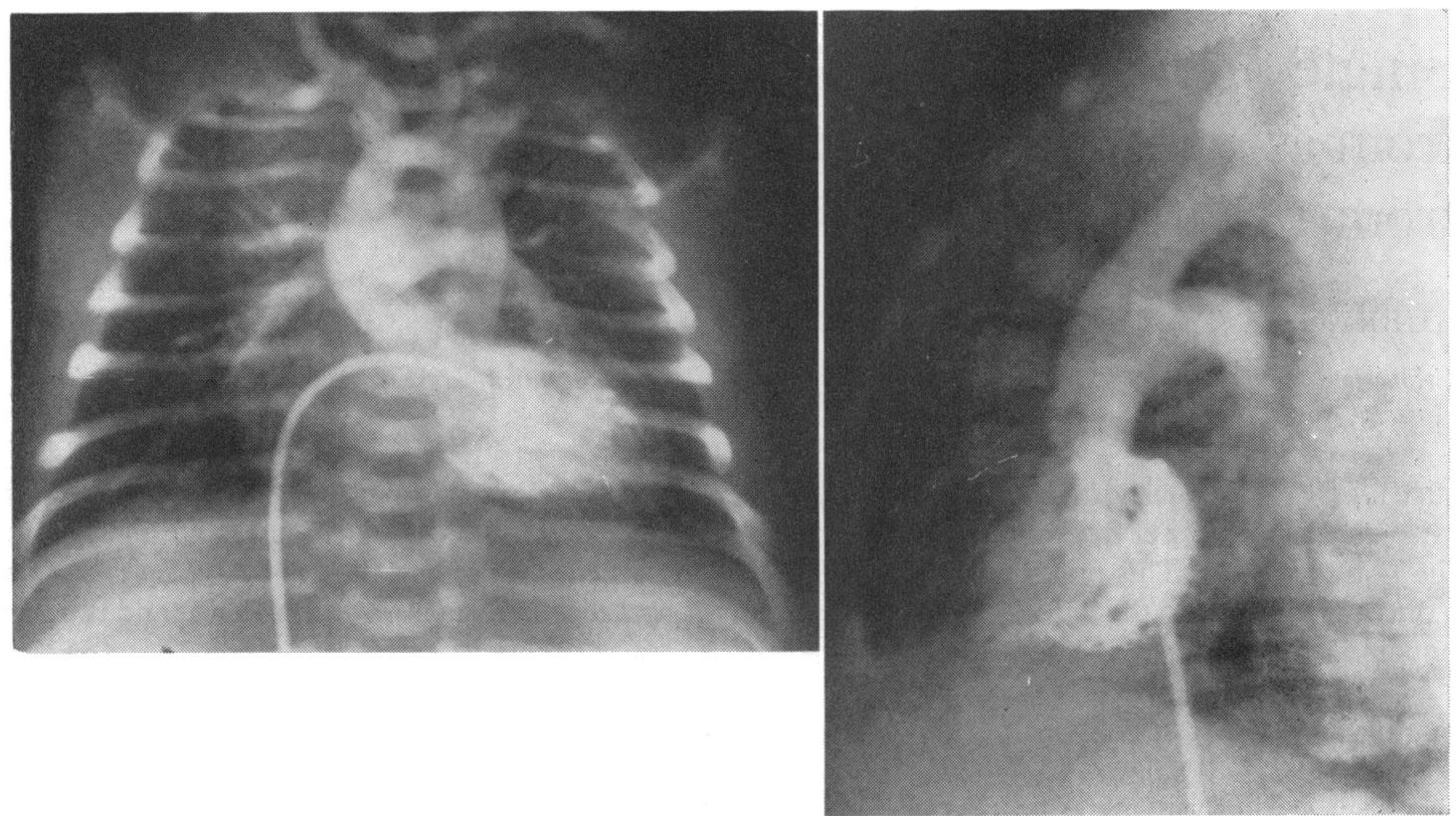

Fig. 1a and $\mathrm{b}$ Left ventricular injection showing a large vessel supplying right and left pulmonary arteries arising from the posterior aspect of the ascending aorta. An intact interventricular septum, left aortic arch, and moderate coarctation can also be seen.

(a)

(b)
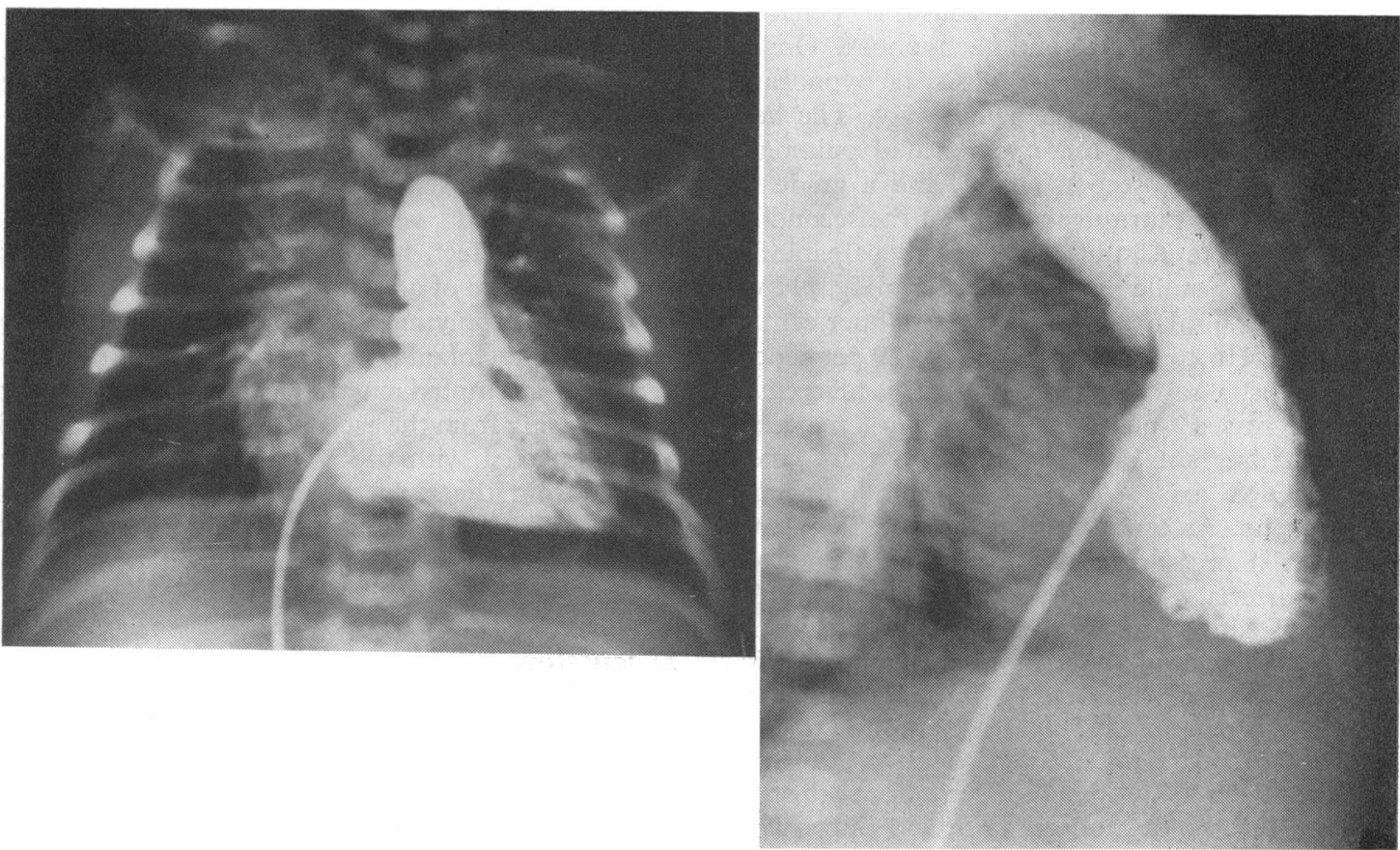

Fig. 2a and $\mathrm{b}$ Right ventricular injection showing a large right ventricle and main pulmonary trunk without pulmonary artery branches to the lungs. Opacification of ascending aorta via a persistent ductus arteriosus. 


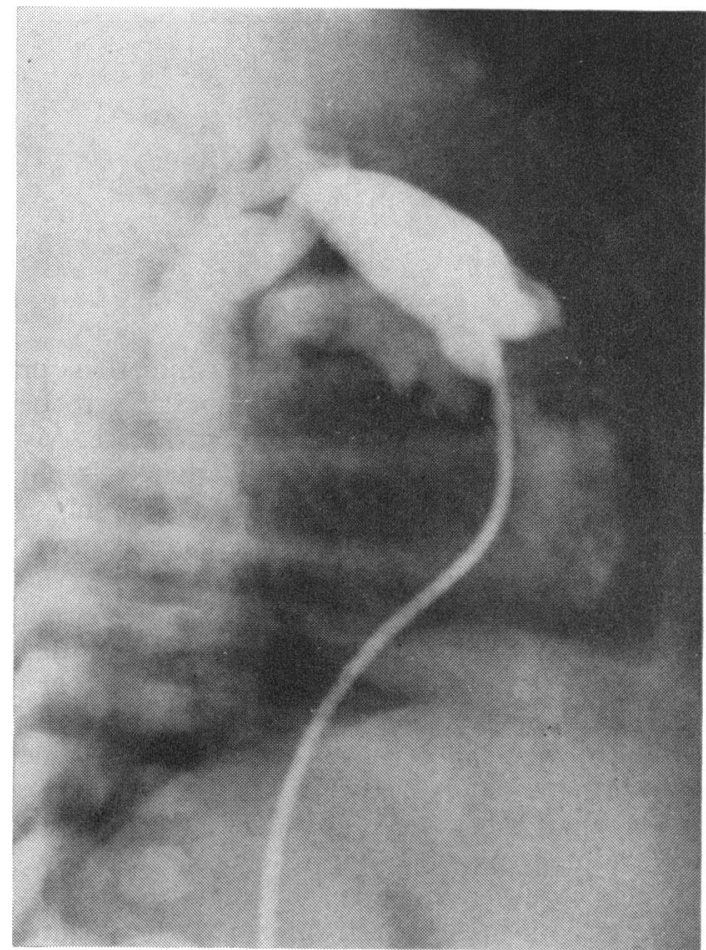

Fig. 3 Injection into the pulmonary trunk showing both aortic and pulmonary valves, with the abnormal vessel arising from ascending aorta and a hypoplastic isthmus.

1974), this anomaly has not to our knowledge been previously described.

Any embryological explanation for its anatomy is speculative. In the normal heart the pulmonary trunk is derived primarily from septation of the truncus arteriosus while the intrapulmonary vessels develop in situ. Later during development the proximal part of the left sixth aortic arch is adsorbed into the wall of the pulmonary trunk while its distal part persists as the ductus arteriosus. Thus the definitive left pulmonary artery is derived solely from intrapulmonary vessels. In contrast the right main pulmonary artery is derived from the proximal part of the right sixth aortic arch, the distal portion of which normally undergoes involution. The intrapulmonary vessels normally join the paired sixth aortic arches at the junction of their proximal and distal parts. Septation of the truncus arteriosus is by two bulbotruncal ridges, abnormal orientation of which has been suggested as the basis for origin of the right pulmonary artery from the ascending aorta
(Cucci et al., 1964). In all examples of this latter group, however, the pulmonary trunk gave rise to the left pulmonary artery. When a left-sided ductus arteriosus was present as well (Sanger et al., 1965; Winship et al., 1967; Kuypers et al., 1969; Keane et al., 1974) the complete left sixth aortic arch appears to have persisted.

Our case differs from these in that the left-sided intrapulmonary artery has no connection to the pulmonary trunk. A possible explanation for this is that the vessel arising dorsally from the ascending aorta represents the proximal part of the right sixth aortic arch in normal connection with the right intrapulmonary vessels. The complete left sixth arch is present as part of the pulmonary trunk and persistent ductus arteriosus. The left-sided intrapulmonary vessels however have come into abnormal connection with the proximal right sixth arch. There is some evidence for this theory. In our patient the right pulmonary artery appears shorter and the left pulmonary artery longer and more horizontal than in the normal (Fig. 1a). This could reflect failure of leftward migration of the proximal right sixth arch and excessive rightward migration of the left-sided intrapulmonary vessels.

\section{References}

Cucci, C. E., Doyle, E. F., and Lewis, E. W., Jr. (1964). Absence of a primary division of the pulmonary trunk. An ontogenetic theory. Circulation, 29, 124-131.

Flege, J. B., Jr., Durnin, R. E., and Rossi, N. P. (1970). Aortic origin of the right pulmonary artery and ventricular septal defect. Fournal of Thoracic and Cardiovascular Surgery, 59, 468-573.

Keane, J. F., Maltz, D., Bernhard, W. F., Corwin, R. D., and Nadas, A. S. (1974). Anomalous origin of one pulmonary artery from the ascending aorta. Diagnostic, physiological and surgical considerations. Circulation, 50, 588-594.

Kuers, P. F. W., and McGoon, D. C. (1973). Tetralogy of Fallot with aortic origin of the right pulmonary artery. Surgical implications. Fournal of Thoracic and Cardiovascular Surgery, 65, 327-331.

Kuypers, P. J., van der Maas, A. H., and Busch, H. J. (1969). Origin of the right pulmonary artery from the aorta with patent ductus arteriosus. Fournal of Thoracic and Cardiovascular Surgery, 57, 185-189.

Sanger, P. W., Taylor, F. H., Robicsek, F., and Najib, A. (1965). Aortic origin of the right pulmonary artery with patent ductus arteriosus. Annals of Thoracic Surgery, 1, 179-183.

Winship, W. S., Beck, W., and Schrire, V. (1967). Congenital 'Absence' and anomalous origin of the main pulmonary arteries. Variations of the same congenital defect. British Heart fournal, 29, 34-42.

Requests for reprints to $\mathrm{Dr} A$. Beitzke, Univ.Kinderklinik, A-8036, Graz, Austria. 